\title{
Botulinum toxin for upper oesophageal sphincter dysfunction in neurological swallowing disorders (Review)
}

\author{
Regan J, Murphy A, Chiang M, McMahon BP, Coughlan T, Walshe M
}

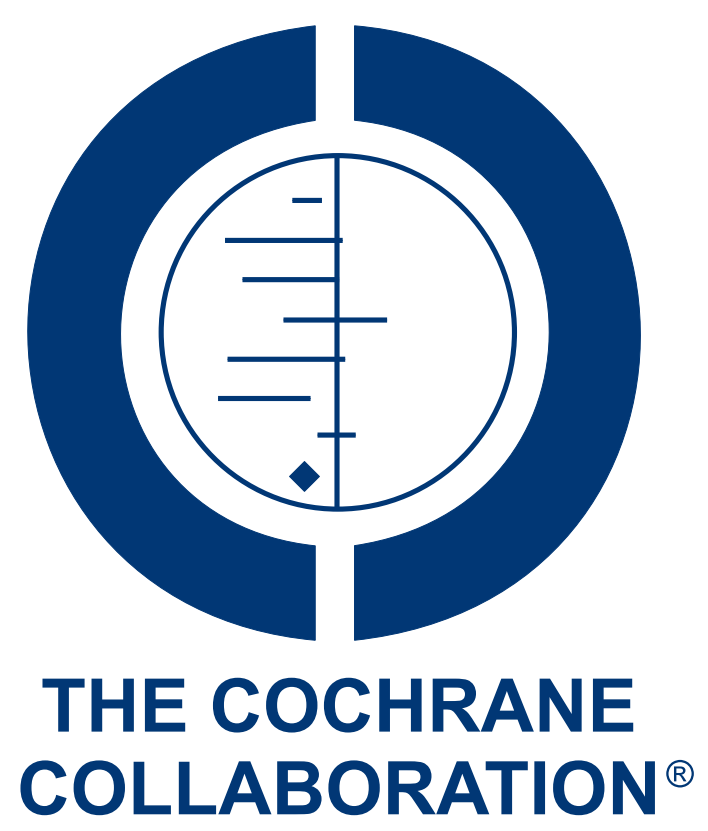

This is a reprint of a Cochrane review, prepared and maintained by The Cochrane Collaboration and published in The Cochrane Library 2014, Issue 5

\section{WILEY}

Botulinum toxin for upper oesophageal sphincter dysfunction in neurological swallowing disorders (Review) 
TABLE OF CONTENTS

HEADER . . . . . . . . . . . . . . . . . . . . . . . . . . . . . . . . . . . . . . . 1

ABSTRACT . . . . . . . . . . . . . . . . . . . . . . . . . . . . . . . . . 1

PLAIN LANGUAGE SUMMARY..$\quad$. . . . . . . . . . . . . . . . . . . . . . . . . . . . . . . . . . . . . $\quad 2$

SUMMARY OF FINDINGS FOR THE MAIN COMPARISON ．．．．．．．．．．．．．．．．．． . 3

BACKGROUND . . . . . . . . . . . . . . . . . . . . . . . . . . . . . . . . . . . 3

OBJECTIVES . . . . . . . . . . . . . . . . . . . . . . . . . . . . . . . . . . . . . 5

METHODS . . . . . . . . . . . . . . . . . . . . . . . . . . . . . . . . . . . . . 5

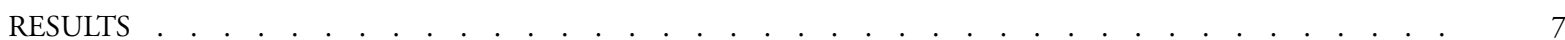

Figure 1. . . . . . . . . . . . . . . . . . . . . . . . . . . . . . . . . . . . . . 8

DISCUSSION . . . . . . . . . . . . . . . . . . . . . . . . . . . . . . . . . . . . . 9

AUTHORS' CONCLUSIONS . . . . . . . . . . . . . . . . . . . . . . . . . . . . . . . . . 9

REFERENCES . . . . . . . . . . . . . . . . . . . . . . . . . . . . . . . . . . . . . 10

CHARACTERISTICS OF STUDIES . . . . . . . . . . . . . . . . . . . . . . . . . . . . . . . . . . . . . 13

DATA AND ANALYSES . . . . . . . . . . . . . . . . . . . . . . . . . . . . . . . . . . . . . . . 16

APPENDICES . . . . . . . . . . . . . . . . . . . . . . . . . . . . . . . . . . . . . 16

CONTRIBUTIONS OF AUTHORS . . . . . . . . . . . . . . . . . . . . . . . . . . . . . . . . . . . . . . . 26

DECLARATIONS OF INTEREST . . . . . . . . . . . . . . . . . . . . . . . . . . . . . . . . . . . . . . . 26

SOURCES OF SUPPORT . . . . . . . . . . . . . . . . . . . . . . . . . . . . . . . . . . . . . . . 26

Botulinum toxin for upper oesophageal sphincter dysfunction in neurological swallowing disorders (Review)

Copyright @ 2014 The Cochrane Collaboration. Published by John Wiley \& Sons, Ltd. 


\title{
[Intervention Review] \\ Botulinum toxin for upper oesophageal sphincter dysfunction in neurological swallowing disorders
}

\author{
Julie Regan ${ }^{1,2}$, Anne Murphy ${ }^{3}$, Mindy Chiang ${ }^{2}$, Barry P McMahon ${ }^{4,5}$, Tara Coughlan ${ }^{6}$, Margaret Walshe ${ }^{2}$ \\ ${ }^{1}$ Speech \& Language Therapy Department, Tallaght Hospital, Dublin, Ireland. ${ }^{2}$ Clinical Speech and Language Studies, Trinity College \\ Dublin, Dublin, Ireland. ${ }^{3}$ Tallaght Hospital Library, Tallaght Hospital, Dublin, Ireland. ${ }^{4}$ Medical Physics \& Clinical Engineering, \\ Tallaght Hospital, Dublin, Ireland. ${ }^{5}$ Department of Clinical Medicine, Trinity College Dublin, Dublin, Ireland. ${ }^{6}$ Age Related Health \\ Care, Tallaght Hospital, Dublin, Ireland
}

Contact address: Julie Regan, reganju@tcd.ie.

Editorial group: Cochrane Upper Gastrointestinal and Pancreatic Diseases Group.

Publication status and date: New, published in Issue 5, 2014.

Review content assessed as up-to-date: 31 July 2013.

Citation: Regan J, Murphy A, Chiang M, McMahon BP, Coughlan T, Walshe M. Botulinum toxin for upper oesophageal sphincter dysfunction in neurological swallowing disorders. Cochrane Database of Systematic Reviews 2014, Issue 5. Art. No.: CD009968. DOI: 10.1002/14651858.CD009968.pub2.

Copyright $@ 2014$ The Cochrane Collaboration. Published by John Wiley \& Sons, Ltd.

\begin{abstract}
A B S T R A C T
Background

Adequate upper oesophageal sphincter (UOS) opening is critical to safe and efficient swallowing due to the close proximity of the UOS to the airway entrance. Many people with neurological conditions, progressive and non-progressive, present with UOS dysfunction. The consequences for the person include difficulty swallowing food with subsequent choking and aspiration (passage of material into the trachea beyond the level of the true vocal cords). Clinical complications include aspiration pneumonia, weight loss, dehydration and malnutrition. Tube feeding is often indicated but is associated with increased mortality. Quality of life is also frequently impacted. A range of interventions exist that aim to improve UOS function and swallowing. These include compensatory strategies, rehabilitation techniques, pharmacological interventions and surgery. Over the last two decades, botulinum toxin has been gaining popularity as an intervention for UOS dysfunction, with some evidence to suggest that it is successful in improving swallow function. Despite a number of studies investigating its efficacy, there is a lack of consensus regarding whether this intervention is effective in improving swallowing for individuals with UOS dysfunction associated with neurological disease.
\end{abstract}

\section{Objectives}

To establish the efficacy and safety of botulinum toxin use aimed at improving UOS dysfunction in people with swallowing difficulties (dysphagia) associated with non-progressive and progressive neurological disease.

\section{Search methods}

We searched the following electronic databases for published trials: the Cochrane Central Register of Controlled Trials (CENTRAL); Ovid MEDLINE (1950 to 2013); EMBASE (1980 to 2013); AMED (Allied and Complementary Medicine) (1941 to 2013); CINAHL (Cumulative Index to Nursing and Allied Health Literature) (1937 to 2013). We also searched major clinical trials registers: CCT (http://www.controlled-trials.com); Clinical Trials (http://www.clinicaltrials.gov); Chinese Clinical Trial Register (www.chictr.org); ACTR (http://www.actr.org.au/. We examined the reference lists of all potentially relevant studies to identify further relevant trials. We handsearched published abstracts of conference proceedings from both the Dysphagia Research Society and the European Society of Swallowing Disorders. Digestive Disease Week (published in Gastroenterology) was also handsearched. Additionally, we searched ProQuest Dissertations \& Theses for dissertation abstracts.

Botulinum toxin for upper oesophageal sphincter dysfunction in neurological swallowing disorders (Review)

Copyright (c) 2014 The Cochrane Collaboration. Published by John Wiley \& Sons, Ltd. 


\section{Selection criteria}

Only randomised controlled trials were sought.

\section{Data collection and analysis}

Independent searches were completed by JR, AM, MC and MW. Two review authors (JR and MW) independently inspected titles, abstracts and key words identified from the literature search.

\section{Main results}

No randomised controlled studies were retrieved. Twenty-nine studies were excluded, mainly on the basis of trial design.

\section{Authors' conclusions}

It was not possible to reach a conclusion on the efficacy and safety of botulinum toxin as an intervention for people with UOS dysfunction and neurological disease. There is insufficient evidence to inform clinical practice. Directions for future research are provided.

\section{PLAIN LANGUAGE SUMMARY}

\section{Botulinum toxin for swallowing disorders}

Many people have problems swallowing because of an impairment of the upper oesophageal sphincter (UOS), a high pressure zone within the tube that carries food from the mouth to the stomach. Many people with neurological conditions such as stroke, traumatic brain injury, Parkinson's disease or multiple sclerosis can have UOS impairment. This results in difficulty swallowing food and liquids, resulting in choking and food entering into the lungs (aspiration). This has serious consequences for the patient and can cause dehydration, malnutrition and aspiration pneumonia. The person's quality of life can be affected as they are unable to have food or liquids safely by mouth. Tube feeding and hospitalisation is often required.

Many interventions are used to improve UOS function. These include surgery, medications including botulinum toxin, rehabilitation exercises, diet modification and other compensatory techniques.

There is no clear consensus on whether botulinum toxin is safe and effective in managing UOS dysfunction in people with neurological conditions. This makes it hard to decide which intervention will be safest and most effective to improve swallowing and quality of life.

Only randomised controlled trials were sought for inclusion in this review. Trials were looked for through electronic searches of databases, searches of clinical trials registers, from peer reviewed journals, published conference proceedings and reference lists of relevant articles. No trials met the inclusion criteria for the review.

There is insufficient evidence to support the use of botulinum toxin to improve swallowing in people with UOS dysfunction and neurological disease. The lack of trials does not mean that this intervention is ineffective. Adequately powered well designed trials are required. In addition to using sensitive measures looking at changes in swallow function, measures are needed that examine client and caregiver satisfaction, changes in quality of life, psychological well-being and unwanted symptoms associated with the intervention. 
Botulinum toxin compared with other dysphagia interventions for upper oesophageal sphincter dysfunction in neurological swallowing disorders

Patient or population: adults with oro-pharyngeal dysphagia secondary to acute neurological disease Settings:

Intervention: botulinum toxin

Comparison: other dysphagia interventions

Comments

Currently, no evidence is available to support the routine use of botulinum toxin to treat neurogenic dysphagia. Methodologically sound randomised controlled trials are urgently required in order to verify its safety and clinical value across various adult neurogenic groups and to determine optimal candidacy and protocols

\section{B A C K G R O U N D}

\section{Description of the condition}

The upper oesophageal sphincter (UOS), or pharyngo-oesophageal segment (POS), is defined physiologically as a high pressure zone forming a barrier between the pharynx and the oesophagus. This obstruction prevents diversion of air into the oesophagus during inspiration. It also protects the airway from any retrograde passage of material refluxed from the oesophagus or stomach (Singh 2005). Three muscles contribute to the formation of the UOS, the cricopharyngeus (CP) muscle; the most inferior muscle fibres of the inferior pharyngeal constrictor muscle; and the most superior portion of the longitudinal oesophageal muscular fibres (Sivarao 2000). First described by Valsalva in 1717, the cricopharyngeus is the main component of the UOS. Arising from the lateral borders of the cricoid lamina, it is a C-shaped muscle which forms a sling around the wall of the superior aspect of the cervical oesophagus (Sivarao 2000). At rest the sphincter has a slit-like configuration, with the $\mathrm{CP}$ making up the lateral and posterior walls and the cricoid lamina positioned anteriorly. The CP is bordered superiorly by the inferior constrictor muscle and merges inferiorly with the muscular layers of the cervical oesophagus. While the UOS is normally in a tonic state of contraction, it relaxes intermittently to allow trans-sphincteric flow of fluid or gas during antegrade (for example swallowing) and retrograde (for example emesis or belching) events (Cook 2000).

In order for the swallow to be safe and efficient, the UOS needs to open adequately to allow material to pass from the pharynx into the oesophagus. Adequate UOS opening is critical to safe and efficient swallowing due to the close proximity between the UOS and the airway entrance. Manofluoroscopic studies have demonstrated that UOS opening occurs by a combination of CP relaxation, anterior and superior hyolaryngeal excursion and bolus pressure (Cook 1989). In the initial relaxation phase, there is vagal inhibition of the tonic contraction of the $\mathrm{CP}$ muscle, as observed by needle electromyography (EMG) (Ertekin 2002). This precedes UOS opening by $200 \mathrm{msec}$ and lasts 300 to $600 \mathrm{msec}$. In the second phase, UOS opening occurs via the biomechanics of hyolaryngeal excursion (Cook 1989). The suprahyoid muscles (geniohyoid, mylohyoid, stylohyoid, hyoglossus and the anterior belly of the digastric) contract causing the hyoid bone to be pulled both anteriorly and superiorly. This movement, paired with contraction of the thyrohyoid, an infrahyoid muscle which is the main connection between the hyoid bone and the larynx, pulls the laryngeal complex in a superior and anterior direction. As the UOS is connected to the laryngeal complex via $\mathrm{CP}$ muscle attachment to the cricoid cartilage, the anterior portion of the UOS is pulled open. The UOS assumes an oval cross section and is raised 2 to $2.5 \mathrm{~cm}$ in an orad direction. In the third distension phase, pressure applied by the weight and volume of the onrushing bolus distends the lumen of the UOS. This distension collapses in the fourth phase as the bolus passes through the sphincter. Finally, in the fifth phase the UOS closes as the cricopharyngeus actively contracts (Cook 1989).

UOS dysfunction during swallowing has been reported in numerous acute and progressive neurological conditions including, but not limited to, brainstem stroke (Bian 2009), motor neuron disease (Higo 2002), Parkinson's disease (Restivo 2002), myasthenia gravis (Colton-Hudson 2002) and inclusion body myositis (Oh 
2008). The prevalence of UOS dysfunction in people with neurological dysphagia (difficulty swallowing) varies in the literature as rates depend on the definitions of UOS used, the heterogeneity in neurological populations studied and the evaluation methods employed. For example, the reported prevalence for UOS dysfunction in people with Parkinson's disease varies from 21\% (Ali 1996) to $43 \%$ (Higo 2001), and in stroke from $15 \%$ (Steinhagen 2009) to $44 \%$ (Bian 2009). Diagnosis of UOS dysfunction cannot be made from a clinical swallow examination as the sensitivity and specificity of this examination are extremely poor in predicting UOS dysfunction. Videofluoroscopy, fibreoptic endoscopic evaluation of swallowing (FEES), manometry (Butler 2009) and EMG (Ertekin 2002) are the most commonly employed instrumental evaluations to evaluate UOS function for swallowing. The causes of impaired UOS opening vary across neurological conditions and can result from disordered neurally-mediated CP muscle relaxation, suboptimal anterior and superior hyolaryngeal excursion, weak bolus propulsion, cricopharyngeal fibrosis or a combination of these factors (Cook 2000). Dysphagia frequently results, characterised by the prevention of material passing safely and efficiently from the pharynx into the oesophagus during swallowing. Solid food can pose particular problems and can lead to choking and multiple swallowing. This typically leads to aspiration (passage of material into the trachea beyond the level of the true vocal cords), post-swallow and pharyngeal retention of material. Clinical complications include aspiration pneumonia, weight loss, dehydration, malnutrition, the need for tube feeding and increased mortality (Martino 2005; Smithard 1996). Quality of life is also frequently affected (Leow 2010).

Management of impaired UOS opening during swallowing varies across individuals and intervention can be pharmacological, compensatory, rehabilitative or surgical in nature. Frequently it involves a combination of these methods. Compensation includes the use of postural strategies (for example head turn, chin tuck) (McCulloch 2010) and voluntary manoeuvres (for example effortful swallow) (Hiss 2005), which are employed clinically to improve and prolong UOS opening hence minimising aspiration and facilitating bolus clearance during swallowing. Rehabilitation programs designed to target impaired UOS opening during swallowing include jaw exercises (Wada 2012), the Shaker 'head lifting' exercises (Shaker 1997; Shaker 2002) and the Mendelsohn manoeuvre (Kahrilas 1991). The Shaker exercises are isokinetic and isometric head lifting manoeuvres designed to strengthen the suprahyoid muscles (that is the mylohyoid, geniohyoid, stylohyoid and anterior belly of digastric) and infrahyoid muscles (that is the thyrohyoid), which pull open the UOS during swallowing. The Mendelsohn manoeuvre involves purposeful prolongation of the anteriosuperior displacement of the larynx at mid-swallow. In cases where patients have demonstrated little or no benefit from a trial period of rehabilitation, among other factors, they may be considered for surgical or pharmaceutical interventions to optimise UOS opening. Surgical approaches employed to treat UOS dysfunction com- prise cricopharyngeal myotomy (Kelly 2000; Kos 2010) and upper oesophageal dilatation (Hatlebakk 1998; Hu 2010). Pharmacological treatment consists of botulinum toxin injections into the CP muscle to improve UOS opening during swallowing (Alberty 2000; Alfonso 2010; Krause 2008; Moerman 2006).

\section{Description of the intervention}

While there are seven different subtypes of botulinum toxin, botulinum toxin A (BTA) is the most commonly used subtype in the treatment of UOS dysfunction. While botulinum toxin B (BTB) is used to treat conditions such as cervical dystonia and drooling, particularly when patients have developed a resistance to BTA (Costa 2005), it is used less widely in clinical practice to treat UOS dysfunction. BTA formulations that are available include Botox ${ }^{\circledR}$ (Allergan Inc) and Dysport ${ }^{\circledR}$ (Ipsen Ltd). These products differ in terms of molecular structure and manufacturing processes, and use different methods for determining biological activity (Heinen 2006). One unit of Botox $\AA$ is estimated to be comparable to three to four units of Dysport ${ }^{\circledR}$ (Fuster Torres 2007). Schneider 1994 initially described the use of BTA for the treatment of CP dysphagia, resulting in a temporary relaxation of the $\mathrm{CP}$ musculature and improved opening of the UOS during swallowing. Seventy per cent of participants had more efficient bolus transport into the oesophagus during swallowing and reduced aspiration events. The intervention usually brings improvement in deglutition but most patients require reinjection in three to five months (Krause 2008). Also, reported side effects include inadvertent injection outside the cricopharyngeus, which may result in temporary paralysis of the laryngeal musculature causing dysphonia and, rarely, aspiration. In cases where there is uncertainty regarding the diagnosis of impaired UOS dysphagia, a positive response to a trial of botulinum toxin treatment can suggest candidacy for cricopharyngeal myotomy (Krause 2008).

Since this initial 1994 study, cricopharyngeal BTA injection has been reported in over 200 patients with dysphagia of varying aetiologies with success rates between $43 \%$ and $100 \%$ (Alberty 2000; Alfonso 2010; Chiu 2004; Krause 2008). However, studies have recruited heterogeneous diagnostic groups and the candidacy criteria for BTA injections vary considerably across studies. Additionally, BTA brand and dosage (2.5 to 50 units Botox®); 60 to 360 units Dysport $\left.{ }^{\circledR}\right)$, injection site, technique (rigid endoscopy, flexible endoscopy, transcervical with EMG, transcervical computed tomography (CT)-guided) and outcome measure evaluations (videofluoroscopy, manometry, EMG), among other factors, have differed across studies. This has led to confusion regarding the usefulness of this technique.

\section{How the intervention might work}


Botulinum toxin is a neurotoxin that inhibits presynaptic acetylcholine release and hence chemically denervates the motor endplate. Once injected, botulinum toxin binds rapidly to presynaptic cholinergic nerve terminals, impairing the release of acetylcholine (chemical denervation) at the neuromuscular junction. This results in a temporary dose-related weakness or reversible palsy of the innervated muscle. Therapeutic effects are usually seen within three days of the injection. Peripheral neuronal sprouting prevents the effects from being permanent. Reports to date suggest that effects last from two to up to 24 months (Kim 2006; Masiero 2006). BTA has been used effectively in the past for the management of a number of hyperkinetic disorders (for example blepharospasm, torticollis, spasmodic dysphonia) with good results and limited side effects (Jankovic 1991). In more recent times, its use has been expanded to treat UOS dysfunction in neurogenic dysphagia (Alberty 2000; Alfonso 2010; Bian 2009; Kim 2006; Parameswaran 2002; Restivo 2002; Zaninnotto 2004). However, several methodological aspects of these studies vary and its usefulness remains unclear.

\section{Why it is important to do this review}

Clinicians working with people with dysphagia secondary to UOS dysfunction as a result of acute or progressive neurological disease have difficulty determining the efficacy of botulinum toxin injections to treat dysphagia in individuals with neurogenic dysphagia. The most effective formulation, sites for injection, the optimum dosage, the method of delivery (endoscopic or transcutaneous) and the length of time before the effects wear off are as yet undetermined. There are currently no systematic reviews examining the efficacy of botulinum toxin to treat UOS dysfunction in acute or progressive neurological populations despite it being a topical issue. Given that botulinum toxin is being used clinically to treat UOS dysfunction, supported by a limited evidence base, as well as the adverse events associated with the intervention, a systematic review of the evidence is required in this area. Evidence is required not only from a clinical perspective but also to identify the specific direction for future clinical trials and intervention studies in the area.

\section{O B J E C T I V E S}

1. To establish the efficacy and safety of botulinum toxin use aimed at improving UOS dysfunction in people with swallowing difficulties (dysphagia) associated with non-progressive and progressive neurological disease.

2. To provide the best evidence to inform clinical practice.

3. To assist with future research planning.

\section{METHODS}

\section{Criteria for considering studies for this review}

\section{Types of studies}

Only randomised controlled trials (RCTs) were included in the review. An RCT is defined as an experiment in which an intervention (for example botulinum toxin) and one control treatment or no treatment are compared by being randomly allocated to participants. In most trials one intervention is assigned to each individual but sometimes assignment is to defined groups of individuals or both interventions are assigned within individuals (for example in different orders or to different parts of the body). Crossover trials would only be included if the washout period of the botulinum toxin was known.

We did not apply any language limits on published studies or date restrictions on trials.

\section{Types of participants}

We planned to include all trials involving adults (18 years or older), both male and female, with oro-pharyngeal dysphagia secondary to acute (for example stroke, traumatic brain injury (TBI)) non-progressive and progressive neurological disease (for example Parkinson's disease, motor neuron disease, multiple sclerosis). We excluded trials that included participants with congenital neurological conditions (for example cerebral palsy) as dysphagia in these diagnostic groups is multifactorial.

We excluded trials that included participants with independent or co-morbid non-neurological causes of dysphagia (for example head and neck cancer, tracheostomy, oesophageal disease, a structural abnormality such as pharyngeal or oesophageal diverticulum).

\section{Types of interventions}

\section{Comparisons}

- Botulinum toxin (all subtypes, methods of delivery, injection sites within the UOS, dosages and commerical brands) versus no intervention

- Botulinum toxin versus placebo

- Botulinum toxin versus other intervention (i.e. traditional dysphagia rehabilitation)

- Botulinum toxin and traditional rehabilitation approach versus traditional rehabilitation approach (where traditional rehabilitation was identical in both groups) 


\section{Types of outcome measures}

Binary outcomes were reported for all primary and secondary outcomes.

\section{Primary outcomes}

1. Positive change to oral intake status (Yes or No)

2. Reduction or elimination of aspiration or laryngeal penetration of food or fluids, or both, as rated on objective assessment (videofluoroscopy, fibreoptic examination of swallowing safety (FEES) (Yes or No)

3. Adverse events including increase in swallowing problems, compromised medical health, negative psychological consequences, negative social consequences, hospitalisation, death (Yes or No)

4. Client or carer satisfaction, or both, with intervention (Yes or No)

\section{Secondary outcomes}

1. Reduction or elimination of residue in the valleculae or pyriform sinus, or both, or post-swallow (Yes or No)

2. Positive change in quality of life (Yes or No)

Regarding follow up of intervention effects, three time frames were considered: immediate (< one month), medium term (one to six months) and long term ( $>$ six months). Three time points were included to ensure that the long-lasting effects of botulinum toxin were captured.

\section{Search methods for identification of studies}

\section{Electronic searches}

We searched the following bibliographic databases for published trials:

- the Cochrane Central Register of Controlled Trials (CENTRAL) in The Cochrane Library (August 2013) (Appendix $1)$;

- Ovid MEDLINE (1950 to August 2013) (Appendix 2);

- Elsevier EMBASE (1980 to August 2013) (Appendix 3);

- EBSCO AMED (Allied and Complementary Medicine)

(1941 to August 2013) (Appendix 4);

- EBSCO CINAHL (Cumulative Index to Nursing and

Allied Health Literature) (1937 to August 2013) (Appendix 5).

We searched major clinical trials registers:

- CCT (http://www.controlled-trials.com);

- Clinical Trials (http://www.clinicaltrials.gov);

- Chinese Clinical Trial Register (www.chictr.org);

- ACTR (http://www.actr.org.au/).
The search strategy was developed for Ovid MEDLINE and adapted for use in the CENTRAL, EMBASE, AMED and CINAHL databases. We searched for articles with combinations of subject headings and key words relating to botulinum toxin; and upper oesophageal sphincter; and dysphagia or deglutition or swallowing. We did not apply language limits and used the Cochrane highly sensitive search strategy for identifying randomised controlled trials in Ovid MEDLINE.

\section{Searching other resources}

We scanned the reference lists of all included studies to identify further relevant trials. We handsearched published abstracts of conference proceedings from both the Dysphagia Research Society and the European Society of Swallowing Disorders (both published in Dysphagia). Digestive Disease Week (published in Gastroenterol$o g y$ ) was also handsearched. Additionally, we searched ProQuest Dissertations \& Theses for dissertation abstracts.

\section{Data collection and analysis}

\section{Selection of studies}

Two review authors (JR and MW) independently inspected titles, abstracts and key words identified from the literature search. Duplicate items were removed. The results of the literature search were categorised as 'potentially relevant', 'relevant', and 'not relevant'. If it was unclear from the titles and abstracts whether a study should be included, then we obtained copies of the trials for further assessment. We resolved any disagreement on the selection of studies by consensus discussion. We listed the studies that were excluded in the Characteristics of excluded studies table.

\section{Data extraction and management}

A data extraction form was prepared for data extraction. Two review authors (JR and MW) planned to independently extract details of all included studies and, where practicable, to contact study authors to obtain incomplete details or missing data. It was planned that a third review author would extract data from a random sample of $20 \%$ of included studies.

\section{Assessment of risk of bias in included studies}

It was planned that two review authors would independently assess risk of bias in each included study, addressing the following issues which may be associated with biased estimates of treatment effect: sequence generation; allocation sequence concealment; blinding of participants, personnel and outcome assessors; incomplete outcome data; selective outcome reporting; and other potential threats to validity (Higgins 2011). 


\section{Measures of treatment effect}

We planned to carry out a meta-analysis of the primary and secondary endpoints using risk ratio (RR) and $95 \%$ confidence interval (CI) for dichotomous outcomes, and mean difference (MD) or standardised mean differences (SMD) and 95\% confidence interval (CI) for continuous outcomes.

\section{Unit of analysis issues}

To make sure the analysis matched the level of randomisation, we planned to identify the numerous variations in the design of included studies (simple parallel group design, cluster-randomised trial, repeated measurements, recurring events, etc). As this is a review of a pharmaceutical procedures, we included both cluster-randomised and individually-randomised trials. If cluster-randomised trials were included and the data were analysed appropriately, analysis would be by the generic inverse variance method. Where the same patient was included more than once, only the first episode of treatment would be included and if patients had been allowed to cross over into the other arm, the data would be analysed strictly by an intention-to-treat (ITT) analysis. We would have contacted the original authors whenever necessary and sought input from the Cochrane Upper Gastrointestinal and Pancreatic Diseases Group editorial base for analysis issues involving any included trials with multiple treatment groups and clusterrandomised designs.

\section{Dealing with missing data}

In the event of missing data, we agreed to contact the original trial authors to obtain this data or to seek clarification. Alternatively, we would perform a sensitivity analysis and address the potential impact of the missing data on the findings of the review in the 'Discussion' section, as recommended by the Cochrane Handbook for Systematic Reviews of Interventions (Higgins 2011).

\section{Assessment of heterogeneity}

Heterogeneity tests were planned using a standard $\mathrm{Chi}^{2}$ test (significance at $\mathrm{P}<0.1$ ) or an $\mathrm{I}^{2}$ statistic (heterogeneity at $>50 \%$ ). If there was evidence of heterogeneity, we would explore which factor caused it and perform a subgroup analysis according to the possible reasons.

\section{Assessment of reporting biases}

It was planned to report biases (publication bias, time lag bias, duplicate publication bias, location bias, citation bias, language bias or outcome-reporting bias) and minimise reporting bias through a comprehensive search for studies, inclusion of unpublished studies and use of trial registries. We would evaluate this latter bias using funnel plot asymmetry testing, if necessary.

\section{Data synthesis}

A meta-analysis was planned for all RCTs included in the review, considering all the outcomes listed for data synthesis. We would use a random-effects model for the primary analysis, then use the fixed-effect model as a sensitivity analysis to check that the results were robust regardless of which method was chosen.

\section{Subgroup analysis and investigation of heterogeneity}

We planned to conduct a subgroup analysis focusing on the following:

- endoscopic versus transcutaneous botulinum toxin

injections;

- site of injections;

- needle used;

- botulinum type and formulation;

- dosage of botulinum toxin.

If substantial heterogeneity $\left(\mathrm{Chi}^{2}\right.$ test $\mathrm{P}<0.1$ or an $\mathrm{I}^{2}$ value $>$ $50 \%$ ) existed between studies for the primary outcome (that is aspiration or penetration and oral intake) we would explore the reasons for the heterogeneity, such as severity of dysphagia, age and neurological diagnosis.

\section{Sensitivity analysis}

We planned to undertake sensitivity analysis to explore the potential influences on effect size. If heterogeneity resulted from low quality trials, we would exclude the lowest quality trials from this analysis.

\section{RE S U L T S}

\section{Description of studies}

\section{Results of the search}

Searches were carried out according to the protocol published in August 2013. The electronic search identified 480 citations, shown in Figure 1. Two authors independently reviewed the references and the full texts of 29 studies that were retrieved for further consideration. None met the eligibility criteria for an RCT. 
Figure I. Study flow diagram.

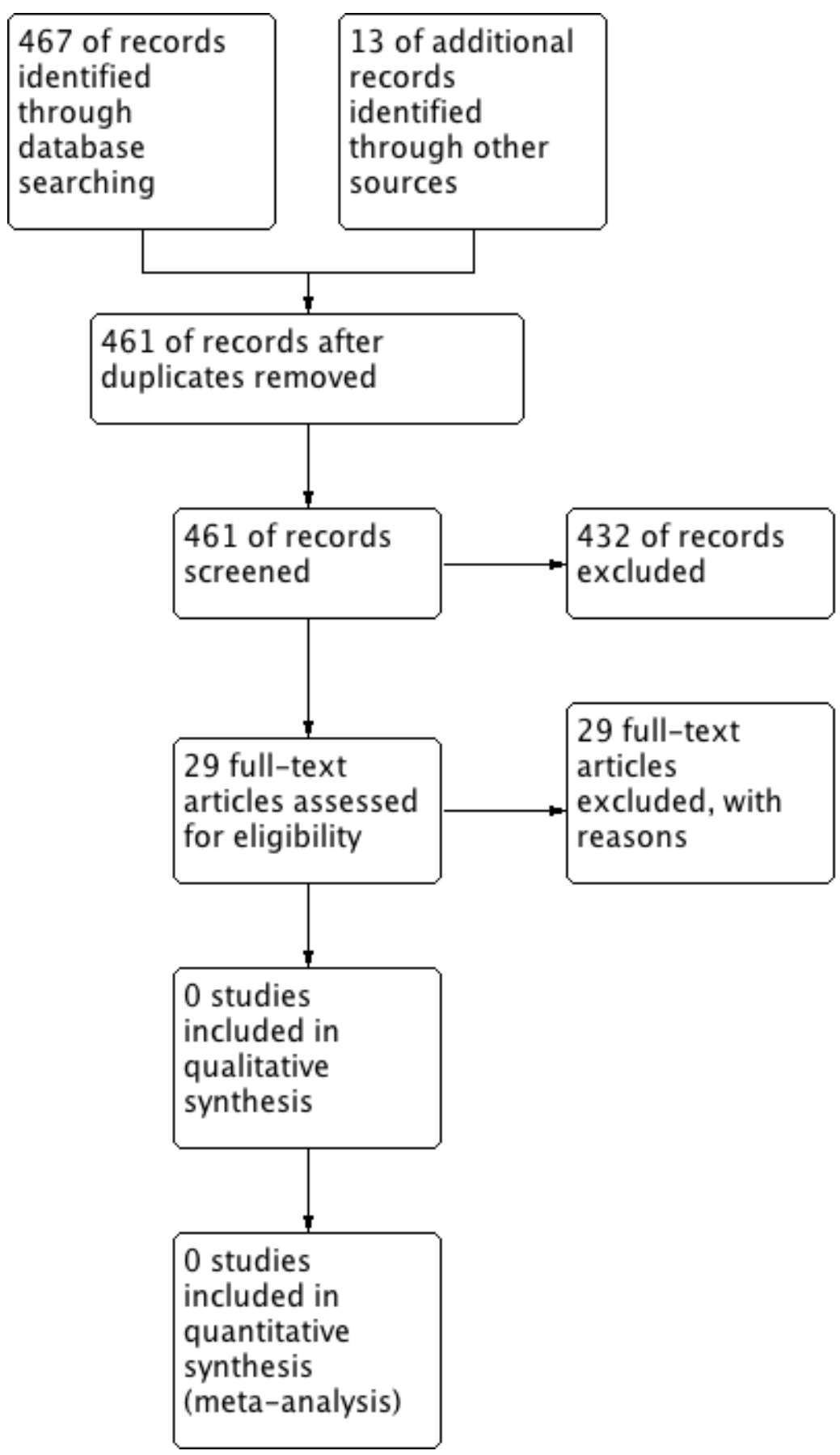




\section{Included studies}

No studies were eligible for inclusion.

\section{Excluded studies}

Twenty-nine studies were excluded following retrieval of the full text reports, details of which appear in the table Characteristics of excluded studies.

\section{Risk of bias in included studies}

There were no included studies, so bias could not be evaluated.

\section{Effects of interventions}

See: Summary of findings for the main comparison There is insufficient evidence to judge the effectiveness of botulinum toxin use to improve UOS dysfunction in people with neurogenic dysphagia.

\section{I S C USSION}

\section{Summary of main results}

No RCTs were retrieved for this review, therefore no conclusions can be reached on the efficacy and safety of botulinum toxin in the treatment of UOS dysfunction and dysphagia in adults with neurological disease. Internationally, there is a growing use of botulinum toxin to treat neurogenic dysphagia. Despite this, there is a lack of methodologically sound evidence to demonstrate the efficacy of this intervention. Specifically, no randomised controlled trials (RCTs) were found which investigated the use of botulinum toxin to treat dysphagia in adult neurological populations. The authors therefore cannot reach any conclusions at this time regarding this intervention.

\section{Overall completeness and applicability of evidence}

The lack of RCTs does not indicate that this intervention is ineffective but rather that RCTs are required on this intervention with this population. Despite the increasing popularity of botulinum toxin as an intervention for UOS dysfunction, there is no evidence-based consensus on the population of adults with UOS dysfunction most suited to this intervention, the differences between the products that are available, whether BTA is preferable to BTB in some populations, the site most suited for injection, the preparation of the solution, ideal dosages, maximum dosage allowed, the safest method of delivery (calibre of needle, number of injection sites etc.) and the use of general anaesthesia versus conscious sedation.

\section{Potential biases in the review process}

The authors are not aware of any potential biases in the review process.

\section{Agreements and disagreements with other studies or reviews}

To the authors' knowledge no other systematic reviews have been completed in this area.

\section{A U THORS' CONCLUSIONS}

\section{Implications for practice}

Despite the large numbers of people receiving botulinum toxin for UOS dysfunction, there are no randomised controlled trials to support this approach. This lack of evidence is both from a clinical and a quality of life viewpoint. Given the potential safety issues associated with this intervention, better evidence is urgently required to support its clinical use.

\section{Implications for research}

Currently, there is no evidence derived from high quality randomised controlled trials to support the routine use of botulinum toxin to treat neurogenic dysphagia. Methodologically sound randomised controlled trials are urgently required in order to verify its safety and clinical value across various adult neurogenic groups and to determine optimal candidacy and protocols.

Randomised controlled trials should address numerous methodological design issues, lacking in clinical studies to date. These include:

- examination of homogeneous clinical groups within studies using clear inclusion and exclusion criteria that might confound data (e.g. presence of tracheostomy);

- precise information regarding the clinical presentation of participants including staging or severity of disease (e.g. time post-acute stroke, stage of Parkinson's disease); 
- clear description of the protocol for administration of botulinum toxin within studies and consistency of the protocols within studies (i.e. administrator, botulinum type and commercial brand, methods of dilution if used, dosage, syringe type and size used, injection site, delivery method (endoscopic or transcutaneous), preparation of patient for procedure with information on whether general anaesthesia or conscious sedation was used);

- use of objective and reliable evaluation tools that can reliably capture UOS opening during swallowing (i.e. videofluoroscopy or FEES);

- psychometrically sound outcome measures must be used; the use of parameters that examine not only changes in the swallow function but the satisfaction of patient and carer with the intervention must also be measured. The impact of the intervention on quality of life and psychological well-being should be included in studies to examine the wider impact of the intervention;

- rigorous methods of randomisation;

- sufficient trial numbers with adequate matching of control and clinical groups;

- blinding of researchers and participants to the intervention received (i.e. placebo or botulinum);

- evaluation post-intervention at multiple time frames (i.e. immediate, medium term and long term intervals);
- if crossover trials are used then the washout period for botulinum toxin must first be established;

- the presence and severity of all adverse effects of botulinum toxin should be reported to enable investigators to calculate the number needed to harm; and so that patients, families and carers can make informed decisions on the risks and side effects associated with the intervention:

- the clients should be followed up for at least 18 months to examine the long term effects of the interventions; follow up should include examination of adverse effects;

- studies examining the number of botulinum toxin injections, and the number of repeat injections needed to maintain UOS function effectively, should be undertaken. These studies should consider the washout period for these interventions and systematically measure the adverse effects of repeated botulinum toxin injections and repeated doses of medications. Measurement of the client and carer satisfaction with these interventions should be included in these studies;

- power calculations should be performed for all studies, with sufficient numbers of participants recruited into trials thus avoiding false negative conclusions;

- data should be analysed on an intention-to-treat basis;

- confidence intervals must be calculated and reported for the results of outcomes;

- all trials should be reported according to the guidelines set out in the CONSORT Statement (Consort 2010).

\section{R E F E R E N C E S}

\section{References to studies excluded from this review}

\section{Ahsan 2000 \{published data only\}}

Ahsan S, Meleca R, Dworkin J. Botulinum toxin injection of the cricopharyngeus muscle for the treatment of dysphagia. Otolaryngology-Head and Neck Surgery 2000;122(5):691-5.

Alberty 2000 \{published data only\}

Alberty J, Oelerich M, Ludwig K, Hartmann S, Stoll

W. Efficacy of botulinum toxin A for treatment of upper esophageal sphincter dysfunction. Laryngoscope 2000;110 (7):1151-6.

Alfonsi 2010 \{published data only\}

Alfonsi E, Merlo IM, Ponzio M, Montomoli C, Tassorelli C, Biancardi C, Lozza A, Martignoni E. An electrophysiological approach to the diagnosis of neurogenic dysphagia: implications for botulinum toxin treatment. Journal of Neurology, Neurosurgery, and Psychiatry 2010;81(8):54-60.
Aoyagi 2012 \{published data only\}

Aoyagi Y, Tsubahara A, Seki S, Hiraoka T. The trial of lidocaine injection improves the success rate of botulinum toxin injection for dysphagia with upper esophageal sphincter (UES) dysfunction. Dysphagia 2011;26:432-75.

Atkinson 1997 \{published data only\}

Atkinson S, Rees J. Botulinum toxin for cricopharyngeal dysphagia: case reports of CT-guided injection. Journal of Otolaryngology 1997;26(4):273-6.

Blitzer 1997 \{published data only\}

Blitzer R, Brin MF. Use of botulinum toxin for diagnosis and management of cricopharyngeal achalasia. OtolaryngologyHead and Neck Surgery 1997;116(3):328-30.

Chiu 2004 \{published data only\}

Chiu M, Chang Y, Hsiao T. Prolonged effect of botulinum toxin injection in the treatment of cricopharyngeal dysphagia: case report and literature review. Dysphagia 2004;19(1):52-7. 
Di Pede 2012 \{published data only\}

* di Pede C, Bonsangue V, Marchese Ragona R, Mion M, Masiero S. Cricopharyngeal botulinum toxin injection and rehabilitation in patients with severe oropharyngeal dysphagia from inclusion body myositis. Dysphagia 2013; 28:280-335.

\section{Dunne 1993 \{published data only\}} Dunne J, Hayes M, Cameron D. Botulinum toxin A for cricopharyngeal dystonia. Lancet 1993;342(8870):559.

Haapaniemi 2001 \{published data only\} Haapaniemi JJ, Laurikainen EA, Pulkkinen J, Marttila RJ. Botulinum toxin in the treatment of cricopharyngeal dysphagia. Dysphagia 2001;16(3):171-5.

Kelly 2013 \{published data only\}

Kelly E, Koszewski I, Jaradeh S, Merati A, Blumin J, Bock $\mathrm{J}$. Botulinum toxin injection for the treatment of upper esophageal sphincter dysfunction. The Annals of Otology Rhinology, and Laryngology 2013;122(2):100-8.

\section{Kim 2006 \{published data only\}}

Kim DY, Park CI, Ohn SH, Moon JY, Chang WH, Park SW. Botulinum toxin type A for poststroke cricopharyngeal muscle dysfunction. Archives of Physical Medicine and Rehabilitation 2006;87(10):1346-51.

Krause 2008 \{published data only\}

Krause E, Schirra J, Gurkov R. Botulinum toxin A treatment of cricopharyngeal dysphagia after subarachnoid haemorrhage. Dysphagia 2008;23:406-10.

Lee 2009 \{published data only\}

Lee SY, Seo HG, Paik NJ. Botulinum toxin injection for dysphagia: a blinded retrospective videofluoroscopic swallowing study analysis. American Journal of Physical Medicine and Rehabilitation 2009;88(6):491-4.

\section{Liu 2004 \{published data only\}}

Liu L, Tarnopolsky M, Armstrong D. Injection of botulinum toxin $\mathrm{A}$ to the upper esophageal sphincter for oropharyngeal dysphagia in two patients with inclusion body myositis. Canadian Journal of Gastroenterology 2004; 18(6):397-9.

\section{Masiero 2006 \{published data only\}}

Masiero S, Briani C, Marchese-Ragona R, Giacometti P, Costantini M, Zaninotto G. Successful treatment of longstanding post-stroke dysphagia with botulinum toxin and rehabilitation. Journal of Rehabilitation Medicine 2006;38 (3):201-3

Murry 2005 \{published data only\}

Murry T, Wasserman T, Carrau RL, Castillo B. Injection of botulinum toxin $\mathrm{A}$ for the treatment of dysfunction of the upper esophageal sphincter. American Journal of Otolaryngology 2005;26(3):157-62.

Parameswaran 2002 \{published data only\}

Parameswaran MS, Soliman AM. Endoscopic botulinum toxin injection for cricopharyngeal dysphagia. Annals of Otology, Rhinology and Laryngology 2002;111(10):871-4.

\section{Rees 2010 \{published data only\}}

Rees C, French C, Butler S, Hickman M, Wright S. Cricopharyngeal botulinum toxin injection with dilation for globus pharyngeus. Dysphagia (Dysphagia Research Society Conference, 2010) 2010;25:354-98.

Restivo 2006 \{published data only\} Restivo DA, Marchese-Ragona R, Lauria G, Squatrito $S$, Gullo D, Vigneri R. Botulinum toxin treatment for oropharyngeal dysphagia associated with diabetic neuropathy. Diabetes Care 2006;29(12):2650-3.

Restivo 2011 \{published data only\} Restivo DA, Marchese-Ragona R, Patti F, Solaro C, Maimone D, Zappalá G, et al.Botulinum toxin improves dysphagia associated with multiple sclerosis. European Journal of Neurology 2011;18(3):486-90.

Restivo 2013 \{published data only\} Restivo D, Casabona A, Nicotra A, Zappia M, Elia $\mathrm{M}$, Romano $\mathrm{M}$, et al.ALS dysphagia pathophysiology Differential botulinum toxin response. Neurology 2013;80 (7):616-20.

Schneider 1994 \{published data only\}

Schneider I, Thumfart WF, Pototschnig C, Eckel HE. Treatment of dysfunction of the cricopharyngeal muscle with botulinum A toxin: introduction of a new, noninvasive method. The Annals of Otology, Rhinology, and Laryngology 1994;103(1):31-5.

Shaw 2001 \{published data only\} Shaw G, Searl J. Botulinum toxin treatment for cricopharyngeal dysfunction. Dysphagia 2001;16:161-7.

Sjogren 2011 \{published data only\} Sjogren. European Society of Swallowing Disorders. 2011.

Terre 2008 \{published data only\} Terre R, Valles M, Panades A, Mearin F. Long-lasting effect of a single botulinum toxin injection in the treatment of oropharyngeal dysphagia secondary to upper esophageal sphincter dysfunction: A pilot study. Scandinavian Journal of Gastroenterology 2008;43:1296-303.

Terré 2013 \{published data only\} Terré R, Panadés A, Mearin F. Botulinum toxin treatment for oropharyngeal dysphagia in patients with stroke. Neurogastroenterology and Motility 2013;24(11):896-e702.

Woisard-Bassols 2013 \{published data only\} Woisard-Bassols V, Alshehri S, Simonetta-Moreau M. The effects of botulinum toxin injections into the cricopharyngeus muscle of patients with cricopharyngeus dysfunction associated with pharyngo-laryngeal weakness. European Archives of Oto-Rhino-Laryngology 2013;270(3): $805-15$.

Zanninoto 2004 \{published data only\} Zaninotto G, Marchese Ragona R, Briani C, Costantini M, Rizzetto C, Portale G. The role of botulinum toxin injection and upper esophageal sphincter myotomy in treating oropharyngeal dysphagia. Journal of Gastrointestinal Surgery 2004;8(8):997-1006. 


\section{Additional references}

\section{Alfonso 2010}

Alfonsi E, Merlo I, Ponzio M, Montomoli C, Tassorelli C, Biancardi C, et al.An electrophysiological approach to the diagnosis of neurogenic dysphagia; implications for botulinum toxin treatment. Journal of Neurology, Neurosurgery, and Psychiatry 2010;81(1):54-60.

Ali 1996

Ali GN, Wallace KL, Schwartz R, DeCarle DJ, Zagami AS, Cook IJ. Mechanisms of oral-pharyngeal dysphagia in patients with Parkinson's disease. Gastroenterology 1996;110 (2):383-92.

Bian 2009

Bian RX, Choi IS, Kim JH, Han JY, Lee SG. Impaired opening of the upper esophageal sphincter in patients with medullary infarctions. Dysphagia 2009;24(2):238-45.

\section{Butler 2009}

Butler SG, Stuart A, Castell D, Russell GB, Koch K, Kemp

$S$. Effects of age, gender, bolus condition, viscosity, and volume on pharyngeal and upper esophageal sphincter pressure and temporal measurements during swallowing. Journal of Speech Language and Hearing Research 2009;52 (1):240.

\section{Colton-Hudson 2002}

Colton-Hudson A, Koopman WJ, Moosa T, Smith D, Bach D, Nicolle M. A prospective assessment of the characteristics of dysphagia in myasthenia gravis. Dysphagia 2002;17(2): 147-51.

\section{Consort 2010}

Schulz KF, Altman DG, Moher D, for the CONSORT Group. CONSORT 2010 Statement: updated guidelines for reporting parallel group randomised trials. BMJ 2010; 340:698-702.

\section{Cook 1989}

Cook IJ, Dodds WJ, Dantas RO, Massey B, Kern MK, Lang IM, et al.Opening mechanisms of the human upper esophageal sphincter. American Journal of Physiology 1989; 257(5 pt 1):G748-59.

\section{Cook 2000}

Cook IJ. Diagnosis and management of cricopharyngeal achalasia and other upper esophageal sphincter opening disorders. Current Gastroenterology Reports 2000;2:191-5.

\section{Costa 2005}

Costa J, Espírito-Santo C, Borges A, Ferreira JJ, Coelho M, Moore P, et al.Botulinum toxin type B for cervical dystonia. Cochrane Database of Systematic Reviews 2005, Issue 1. [DOI: 10.1002/14651858.CD004315.pub2]

\section{Ertekin 2002}

Ertekin C, Aydogdu I. Electromyography of human cricopharyngeal muscle of the upper esophageal sphincter. Muscle \& Nerve 2002;26(6):729-39.

\section{Fuster Torres 2007}

Fuster Torres MA, Aytes LB, Escoda CG. Salivary gland application of botulinum toxin for the treatment of sialorrhea. Medicina Oral Patologia Oral Y Cirugia Bucal 2007;12(7):E511-7.

\section{Hatlebakk 1998}

Hatlebakk JG, Castell JA, Spiegel J, Paoletti V, Katz PO, Castell DO. Dilatation therapy for dysphagia in patients with upper esophageal sphincter dysfunction-manometric and symptomatic response. Diseases of the Esophagus 1998; $11(4): 254-9$.

\section{Heinen 2006}

Heinen F, Molenaers G, Fairhurst C, Carr L, Desloovere K, et al.European consensus table 2006 for botulinum toxin for children with cerebral palsy. European Journal of Paediatric Neurology 2006;10:215-25.

Higgins 2011

Higgins JPT, Green S (editors). Cochrane Handbook for Systematic Reviews of Interventions Version 5.1.0 [updated March 2011]. The Cochrane Collaboration, 2011. Available from www.cochrane-handbook.org.

Higo 2001

Higo R, Tayama N, Watanabe T, Niimi S. Abnormal elevation of resting pressure at the upper esophageal sphincter of Parkinson's disease patients. European Archives of Otorhinolaryngology 2001;258:552-6.

Higo 2002

Higo R, Tayama N, Watanabe T, Nitou T. Videomanofluorometric study in amyotrophic lateral sclerosis. Laryngoscope 2002;112(5):911-7.

\section{Hiss 2005}

Hiss SG, Huckabee ML. Timing of pharyngeal and upper esophageal sphincter pressures as a function of normal and effortful swallowing in young healthy adults. Dysphagia 2005;20(2):149-56

Hu 2010

Hu HT, Shin JH, Kim JH, Park JH, Sung KB, Song HY. Fluoroscopically guided balloon dilation for pharyngoesophageal stricture after radiation therapy in patients with head and neck cancer. American Journal of Roentgenology 2010;194(4):1131.

\section{Jankovic 1991}

Jankovic J, Brin MF. Therapeutic uses of botulinum toxin. The New England Journal of Medicine 1991;324:1186-94.

\section{Kahrilas 1991}

Kahrilas P, Logemann J, Krugler C, Flanagan E. Volitional augmentation of upper esophageal sphincter opening during swallowing. American Journal of Physiology 1991; 260:G450-6.

\section{Kelly 2000}

Kelly JH. Management of upper esophageal sphincter disorders: indications and complications of myotomy. American Journal of Medicine 2000;108 Suppl 4a:43S-6S.

Kos 2010

Kos MP, David EF, Klinkenberg-Knol EC, Mahieu HF. Long-term results of external upper esophageal sphincter myotomy for oropharyngeal dysphagia. Dysphagia 2010;25 (3):169-76. 


\section{Leow 2010}

Leow L, Huckabee ML, Anderson T, Beckert L. The impact of dysphagia on quality of life in ageing and Parkinson's disease as measured by the Swallowing Quality of Life (SWAL-QOL) Questionnaire. Dysphagia 2010;25(2): 216-20.

Martino 2005

Martino R, Foley N, Bhogal S, Diamant N, Speechley M, Teasell R. Dysphagia after stroke: incidence, diagnosis, and pulmonary complications. Stroke 2005;36(12):2756.

\section{McCulloch 2010}

McCulloch TM, Hoffman MR, Ciucci MR. Highresolution manometry of pharyngeal swallow pressure events associated with head turn and chin tuck. The Annals of Otology, Rhinology, and Laryngology 2010;119(6):369.

\section{Moerman 2006}

Moerman MB. Cricopharyngeal botox injection: indications and technique. Current Opinion in Otolaryngology \& Head and Neck Surgery 2006;14(6):431-6.

\section{Oh 2008}

Oh TH, Brumfield KA, Hoskin TL, Kasperbauer JL, Basford JR. Dysphagia in inclusion body myositis: clinical features, management, and clinical outcome. American Journal of Physical Medicine \& Rehabilitation 2008;87(11): 883.

\section{Restivo 2002}

Restivo DA, Palmeri A, Marchese-Ragona R. Botulinum toxin for cricopharyngeal dysfunction in Parkinson's disease. The New England Journal of Medicine 2002;346(15): 1174-5.

\section{Shaker 1997}

Shaker R, Kern M, Bardan E, Taylor A, Stewart ET, Hoffman RG, et al.Augmentation of deglutitive upper esophageal sphincter opening in the elderly by exercise. American Journal of Physiology 1997;272:G1518-22.

\section{Shaker 2002}

Shaker R, Easterling C, Kern M, Nitschke T, Massey B, Daniels $S$, et al.Rehabilitation of swallowing by exercise in tube-fed patients with pharyngeal dysphagia secondary to abnormal UES opening. Gastroenterology 2002;122(5): 1314-21.

Singh 2005

Singh S, Hamdy S. The upper oesophageal sphincter. Neurogastroenterology \& Motility 2005;17:3-12.

\section{Sivarao 2000}

Sivarao DV, Goyal RK. Functional anatomy and physiology of the upper esophageal sphincter. American Journal of Medicine 2000;108(4a):27S-37S.

\section{Smithard 1996}

Smithard DG, O’Neill PA, Parks C, Morris J, Wyatt R, England R, et al.Complications and outcome after acute stroke: does dysphagia matter?. Stroke 1996;27:1200-4.

\section{Steinhagen 2009}

Steinhagen V, Grossman A, Benecke R, Walter U. Stroke patients swallowing disturbance pattern relates to brain lesion location in acute stroke patients. Stroke 2009;40: 1903-6.

Wada 2012

Wada S, Tohara H, Lida T, Inoue M, Sato M, Ueda

K. Jaw-opening exercise for insuffi cient opening of upper esophageal sphincter. Archives Physical Medical Rehabilitation 2012;93:1995-9.

\section{Zaninnotto 2004}

Zaninotto G, Marchese Ragona R, Briani C, Costantini M, Rizzetto C, Portale G. The role of botulinum toxin injection and upper esophageal sphincter myotomy in treating oropharyngeal dysphagia. Journal of Gastrointestinal Surgery 2004;8(8):997-1006.

* Indicates the major publication for the study 
CHARACTERISTICS OF STUDIES

Characteristics of excluded studies [ordered by study ID]

\begin{tabular}{|c|c|}
\hline Study & Reason for exclusion \\
\hline Ahsan 2000 & Not RCT \\
\hline Alberty 2000 & Not RCT \\
\hline Alfonsi 2010 & Not RCT \\
\hline Aoyagi 2012 & Not RCT \\
\hline Atkinson 1997 & Not RCT \\
\hline Blitzer 1997 & Not RCT \\
\hline Chiu 2004 & Not RCT \\
\hline Di Pede 2012 & Not RCT \\
\hline Dunne 1993 & Not RCT \\
\hline Haapaniemi 2001 & Not RCT \\
\hline Kelly 2013 & Not RCT \\
\hline Kim 2006 & Not RCT \\
\hline Krause 2008 & Not RCT \\
\hline Lee 2009 & Not RCT \\
\hline Liu 2004 & Not RCT \\
\hline Masiero 2006 & Not RCT \\
\hline Murry 2005 & Non RCT \\
\hline Parameswaran 2002 & Not RCT \\
\hline Rees 2010 & Not RCT \\
\hline Restivo 2006 & Not RCT \\
\hline Restivo 2011 & Not RCT \\
\hline Restivo 2013 & Not RCT \\
\hline
\end{tabular}

Botulinum toxin for upper oesophageal sphincter dysfunction in neurological swallowing disorders (Review) 
(Continued)

\begin{tabular}{ll}
\hline Schneider 1994 & Not RCT \\
\hline Shaw 2001 & Not RCT \\
\hline Sjogren 2011 & Not RCT \\
\hline Terre 2008 & Not RCT \\
\hline Terré 2013 & Not RCT \\
\hline Woisard-Bassols 2013 & Not RCT \\
\hline Zanninoto 2004 & Not RCT \\
\hline
\end{tabular}




\section{DATA AND ANALYSES}

This review has no analyses.

\section{A P P E N D I C E S}

\section{Appendix I. CENTRAL search strategy}

1. (deglutition adj5 (disturbance $\$$ or disorder $\$$ or difficult $\$$ or dysfunction $\$$ or impair $\$$ or condition $\$$ or abnormal $\$$ or damage $\$$ or injur\$)).mp.

2. dysphagia.mp.

3. (swallowing adj5 (disturbance $\$$ or disorder $\$$ or difficult $\$$ or dysfunction $\$$ or impair $\$$ or condition $\$$ or abnormal $\$$ or damage $\$$ or injur\$)).mp.

4. deglutition/

5. deglutition disorders/

6. esophageal motility disorders/ or esophageal achalasia/ or esophageal spasm, diffuse/

7. swallow\$.ti,ab.

8. or/1-7

9. pharyngeal muscles/ or esophageal sphincter, upper/

10. cricopharyn $\$$.tw.

11. (uos or ues).tw.

12. esophagus/pp

13. cp muscle.mp.

14. or/9-13

15. exp Botulinum Toxins/

16. (botulin\$ adj2 tox\$).mp.

17. dyspor $\$ . m p$.

18. boto $\$ . m p$.

19. btx.ab,ti.

20. (bont adj1 a).ab.

21. oculinu\$.tw.

22. Neuromuscular Agents/

23. or $/ 15-22$

24. (8 or 14$)$ and 23

\section{Appendix 2. MEDLINE search strategy}

1. randomized controlled trial.pt.

2. randomi*ed.ab.

3. randomi*ed.ti.

4. drug therapy.fs.

5. randomly.ab.

6. trial.ab.

7. groups.ab.

8. or/1-7

9. exp animals/ not humans.sh.

10. 8 not 9

11. (deglutition adj5 (disturbance $\$$ or disorder $\$$ or difficult $\$$ or dysfunction $\$$ or impair $\$$ or condition $\$$ or abnormal $\$$ or damage $\$$ or injur\$)).mp.

Botulinum toxin for upper oesophageal sphincter dysfunction in neurological swallowing disorders (Review) 
12. dysphagia.mp.

13. (swallowing adj5 (disturbance $\$$ or disorder $\$$ or difficult $\$$ or dysfunction $\$$ or impair $\$$ or condition $\$$ or abnormal $\$$ or damage $\$$ or injur\$)).mp.

14. deglutition/

15. deglutition disorders/

16. esophageal motility disorders/ or esophageal achalasia/ or esophageal spasm, diffuse/

17. swallow\$.ti,ab.

18. or/11-17

19. pharyngeal muscles/ or esophageal sphincter, upper/

20. cricopharyn $\$ . t w$.

21. (uos or ues).tw.

22. esophagus/pp

23. cp muscle.mp.

24. or/19-23

25. exp Botulinum Toxins/

26. (botulin\$ adj2 tox\$).mp.

27. dyspor\$.mp.

28. boto\$.mp.

29. btx.ab,ti.

30. (bont adj1 a).ab.

31. oculinu\$.tw.

32. Neuromuscular Agents/

33. or $/ 25-32$

34. 10 and (18 or 24$)$ and 33

\section{Appendix 3. EMBASE search strategy}

1. 'Randomized controlled trial'/exp

2. 'Randomization'/exp

3. Random*:ab,ti

4. 'double-blind procedure'/exp

5. 'single-blind procedure'/exp

6. (doubl* NEAR/1 blind):ab,ti

7. (singl* NEAR/1 blind):ab,ti

8. assign*:ab,ti

9. allocat*:ab,ti

10. trial:ab

11. groups:ab

12. or/1-11

13. 'animal'/exp NOT humans.sh.

14. 12 not 13

15. (deglutition NEAR/5 (disturbance* or disorder* or difficult* or dysfunction* or impair* or condition* or abnormal* or damage* or injur*)):ab,ti

16. dysphagia/de

17. swallowing/de

18. (swallowing NEAR/5 (disturbance* or disorder* or difficult* or dysfunction* or impair* or condition* or abnormal* or damage* or injur*)):ab,ti

19. deglut*:ti,ab

20. 'esophagus motility'/de or esophagus function disorder'/de / or 'esophagus achalasia'/de or 'esophagus spasm'/de

21. swallow*:ti,ab

22. or $/ 15-21$

23. 'pharyngeal muscle'/de or 'upper esophagus sphincter'/de

Botulinum toxin for upper oesophageal sphincter dysfunction in neurological swallowing disorders (Review)

Copyright $\odot 2014$ The Cochrane Collaboration. Published by John Wiley \& Sons, Ltd. 


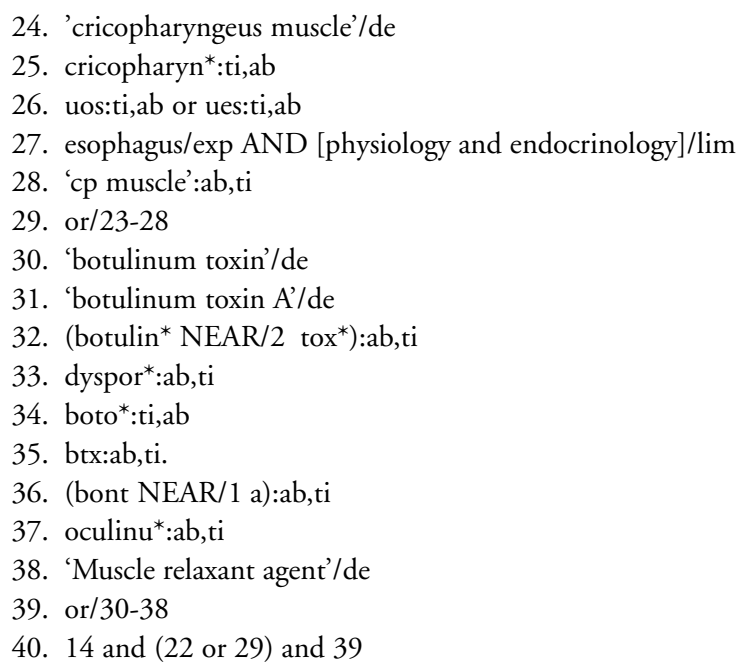

\section{Appendix 4. AMED search strategy}

31. 8 and ( 15 or 21$)$ and 30

30. or/22-29

29. (DE "Neuromuscular Agents")

28. TX oculinu

27. $\mathrm{AB}$ (bont N1 a)

26. TX btx

25. TX boto*

24. TX dyspor*

23. TX (botulin* N2 tox*)

22. (DE "Botulinum Toxins")

21. or/16-20

20. TX 'cp muscle'

19. (DE "esophagus")

18. TX uos or TX ues

17. TX cricopharyn*

16. (DE "pharynx")

15. or/9-14

14. TX swallow*

13. (DE "deglutition disorders")

12. (DE "deglutition")

11. TX (swallowing N5 (disturbance* or disorder* or difficult* or dysfunction* or impair* or condition* or abnormal* or damage* or injur*))

10. TX dysphagia

9. TX (deglutition N5 (disturbance* or disorder* or difficult* or dysfunction* or impair* or condition* or abnormal* or damage* or injur*))

8. or/1-7

7. $\mathrm{AB}$ trial

6. TX randomly

5. TX 'random?ed'

4. (DE "Single blind method)

3. (DE "Double blind method)

2. (DE "Random allocation)

Botulinum toxin for upper oesophageal sphincter dysfunction in neurological swallowing disorders (Review)

Copyright $\odot 2014$ The Cochrane Collaboration. Published by John Wiley \& Sons, Ltd. 


\section{Appendix 5. CINAHL search strategy}

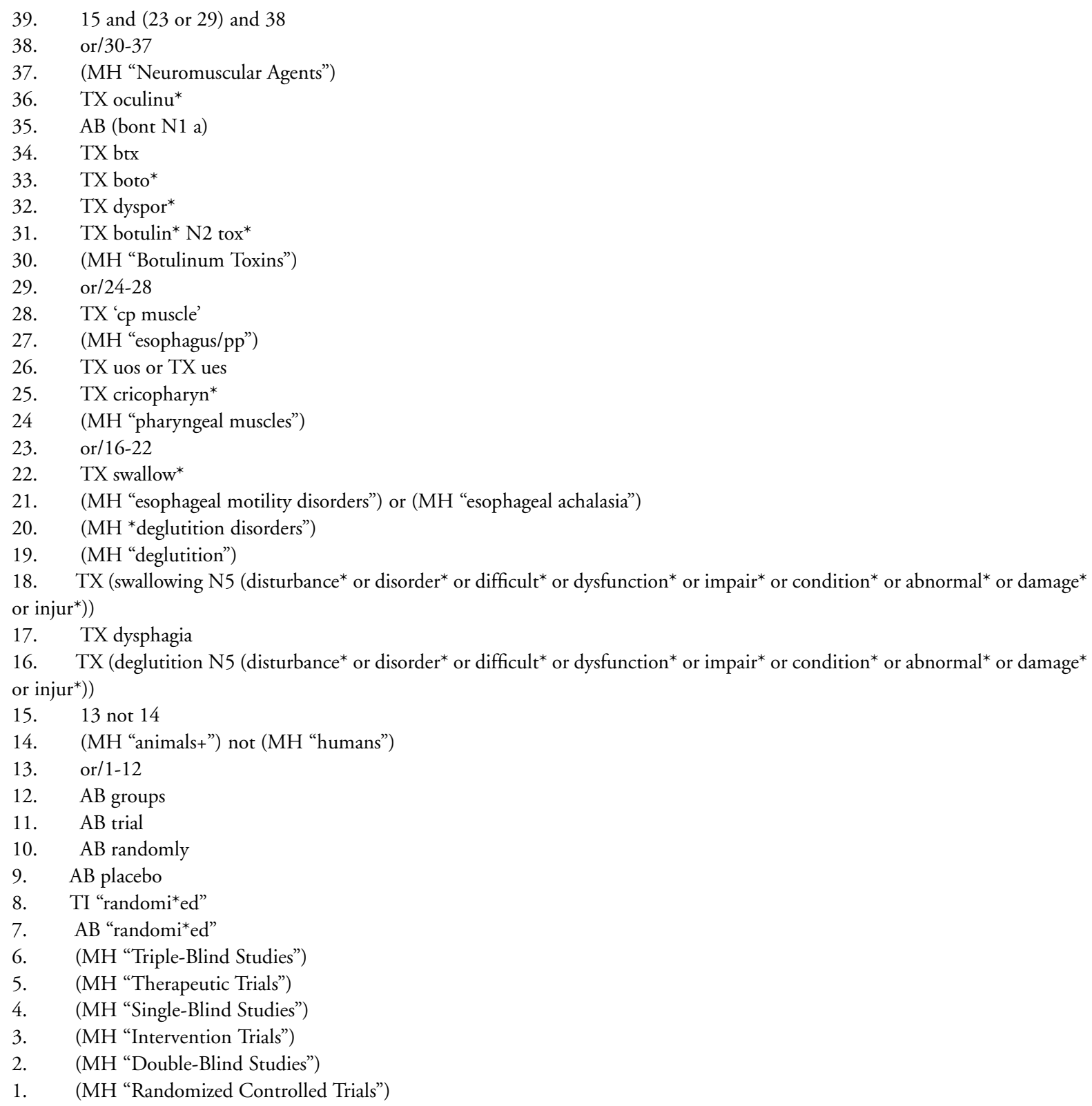




\section{Appendix 6. Data Extraction Form}

Botulinum Toxin for Upper Oesophageal Sphincter Dysfunction in Neurological Swallowing Disorders- Study Selection, Quality Assessment \& Data Extraction Form
Study ID: $\cdots \cdots \cdots \cdots \cdots$
Lead author: ${ }^{\prime}$
Reviewer Initials:
Date or review:

General Study Information

\begin{tabular}{l|l|l|l|l}
\hline First author $\quad$ Year & $\begin{array}{l}\text { Journal/Conference } \\
\text { Proceedings etc }\end{array}$ & Country & Language & Single/Multicentre Trial Study Duration \\
\hline & & & \\
\hline
\end{tabular}

STUDY ELIGIBILITY

\begin{tabular}{l|l|l|l}
\hline RCT & Relevant participants & Relevant interventions & Relevant outcomes \\
\hline Yes / No / Unclear & Yes / No / Unclear & Yes / No / Unclear & Yes / No* / Unclear \\
\hline
\end{tabular}

${ }^{*}$ issue relates to selective reporting - when authors may have taken measurements for particular outcomes, but not reported these within the paper(s). Reviewers should contact trialists for information on possible non-reported outcomes \& reasons for exclusion from publication. Study should be listed in 'Studies awaiting assessment' until clarified. If no clarification is received after three attempts, study should then be excluded.

Do not proceed if any of the above answers are 'No'.

If study to be included in 'Excluded studies' section of the review, record below the information to be inserted into 'Table of excluded studies'.

Participants and trial characteristics

\begin{tabular}{|c|c|c|c|}
\hline \multicolumn{4}{|c|}{ Participant characteristics } \\
\hline \multirow{2}{*}{ Participants : } & Treatment group & Comparison group 1 & Comparison group 2 (N/A) \\
\hline & $\mathrm{N}=$ & $\mathrm{N}=$ & $\mathrm{N}=$ \\
\hline
\end{tabular}


(Continued)

\begin{tabular}{|c|c|c|c|}
\hline $\begin{array}{l}\text { Age } \\
\text { (mean, median, } \\
\text { range, SD): }\end{array}$ & $\begin{array}{l}\text { Mean: } \\
\text { Median: } \\
\text { Range: } \\
\text { SD: }\end{array}$ & $\begin{array}{l}\text { Mean: } \\
\text { Median: } \\
\text { Range: } \\
\text { SD: }\end{array}$ & $\begin{array}{l}\text { Mean: } \\
\text { Median: } \\
\text { Range: } \\
\text { SD: }\end{array}$ \\
\hline $\begin{array}{l}\text { Gender of par- } \\
\text { ticipants: } \\
\text { (numbers / \%, } \\
\text { etc) }\end{array}$ & $\begin{array}{l}\text { Male } \mathrm{N}= \\
\text { Female } \mathrm{N}= \\
\text { Both } \mathrm{N}= \\
\text { Not clear }\end{array}$ & $\begin{array}{l}\text { Male } \mathrm{N}= \\
\text { Female } \mathrm{N}= \\
\text { Both } \mathrm{N}= \\
\text { Not clear }\end{array}$ & $\begin{array}{l}\text { Male } \mathrm{N}= \\
\text { Female } \mathrm{N}= \\
\text { Both } \mathrm{N}= \\
\text { Not clear }\end{array}$ \\
\hline $\begin{array}{l}\text { Rel- } \\
\text { evant neurolog- } \\
\text { ical conditions } \\
\text { within groups : }\end{array}$ & $\begin{array}{l}1 .+\ldots \\
2 .+ \\
3 .\end{array}$ & 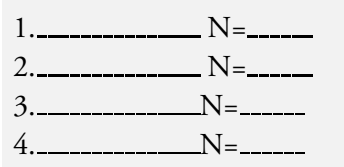 & 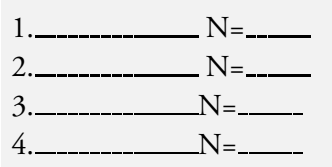 \\
\hline $\begin{array}{l}\text { Can rel- } \\
\text { evant neurolog- } \\
\text { ical dis- } \\
\text { ease groups be } \\
\text { extracted? }\end{array}$ & $\begin{array}{l}\text { Yes } \\
\text { No } \\
\text { Unclear/to contact authors }\end{array}$ & $\begin{array}{l}\text { Yes } \\
\text { No } \\
\text { Unclear/to contact authors }\end{array}$ & $\begin{array}{l}\text { Yes } \\
\text { No } \\
\text { Unclear/to contact authors }\end{array}$ \\
\hline
\end{tabular}

Co-mor-

bidities within

exclusion crite-

ria present/ reported? (e.

g. $\mathrm{H} \& \mathrm{~N} \mathrm{Ca}$, tracheostomy, congenital

neuro condition, oesophageal disease, structural abnormality)

Trial characteristics

\begin{tabular}{|c|c|c|c|}
\hline & Treatment group & Comparison group 1 & $\begin{array}{l}\text { Comparison } \\
\text { group } 2 \text { (N/A) }\end{array}$ \\
\hline $\begin{array}{l}\text { Interventions: } \\
\text { a) botulinum toxin injections } \\
\text { b) placebo intervention } \\
\text { c) dysphagia rehabilitation (de- } \\
\text { scribe nature \& intensity) } \\
\text { d) other }\end{array}$ & a)b)c)d) & $\begin{array}{l}\text { a) } \\
\text { b) } \\
\text { c) } \\
\text { d) }\end{array}$ & $\begin{array}{l}\text { a) } \\
\text { b) } \\
\text { c) } \\
\text { d) }\end{array}$ \\
\hline
\end{tabular}


(Continued)

How was participant eligibility de-

fined?

Type/brand of drug treatment(s)

used?

Dosage of drug treatment?

Method used to identify injection site?

Injection methods (i.e. transcuta-

neous or endoscopic?)

Site of injection?

Size and calibre of needle

Injection administered by:

Time points of measurement col-

lected?

\begin{tabular}{|c|c|c|c|}
\hline $\begin{array}{l}\text { Time-frames considered: } \\
\text { Immediate change (e.g. within one } \\
\text { week) } \\
\text { Medium change } \\
\text { months) } \\
\text { Long term change ( }>6 \text { months) }\end{array}$ & $\begin{array}{l}\text { Yes/ no/ unclear } \\
\text { Yes/ no/ unclear } \\
\text { Yes/ no/ unclear }\end{array}$ & $\begin{array}{l}\text { Yes/ no/ unclear } \\
\text { Yes/ no/ unclear } \\
\text { Yes/ no/ unclear }\end{array}$ & $\begin{array}{l}\text { Yes/ no/ unclear } \\
\text { Yes/ no/ unclear } \\
\text { Yes/ no/ unclear }\end{array}$ \\
\hline
\end{tabular}

Trial design (e.g. parallel / crossover*)

Methodological quality

\begin{tabular}{l|l|l|l}
$\begin{array}{l}\text { STUDY } \\
\text { DESIGN }\end{array}$ & Treatment Group & Comparison Group 1 & Comparison group 2...N/A \\
\hline $\begin{array}{l}\text { Selection bias: } \\
\begin{array}{c}\text { Sequence } \\
\text { generation }\end{array}\end{array}$ & Adequate/Inadequate/Unclear & Adequate/Inadequate/Unclear & Adequate/Inadequate/Unclear \\
$\begin{array}{l}\text { Allocation } \\
\text { concealment }\end{array}$ & Adequate/Inadequate/Unclear & Adequate/Inadequate/Unclear & Adequate/Inadequate/Unclear \\
\hline
\end{tabular}


(Continued)

\begin{tabular}{|c|c|c|c|c|c|c|}
\hline $\begin{array}{l}\text { Performance } \\
\text { Bias } \\
\cdot \quad \text { Blinding of } \\
\text { participants } \\
\text { B Blinding of } \\
\text { other personnel }\end{array}$ & $\begin{array}{l}\text { Yes/No/Unclear } \\
\text { Yes/No/Unclear }\end{array}$ & & $\begin{array}{l}\text { Yes/No/Unclear } \\
\text { Yes/No/Unclear }\end{array}$ & & $\begin{array}{l}\text { Yes/No/Unclear } \\
\text { Yes/No/Unclear }\end{array}$ & \\
\hline $\begin{array}{l}\text { Detection Bias } \\
\text { come measure(s) } \\
\text { apparent } \\
\text { Blind- } \\
\text { ing of outcome } \\
\text { assessors }\end{array}$ & $\begin{array}{l}\text { Yes/No/Unclear } \\
\text { Yes/No/Unclear }\end{array}$ & & $\begin{array}{l}\text { Yes/No/Unclear } \\
\text { Yes/No/Unclear }\end{array}$ & & $\begin{array}{l}\text { Yes/No/Unclear } \\
\text { Yes/No/Unclear }\end{array}$ & \\
\hline $\begin{array}{l}\text { Reporting Bias } \\
\cdot \quad \text { Time lag } \\
\text { to publication } \\
\cdot \quad \text { Language } \\
\text { (Please state) } \\
\cdot \quad \text { Duplicate } \\
\text { publication } \\
\cdot \quad \text { Citation } \\
\text { reporting } \\
\cdot \quad \text { Outcome } \\
\text { reporting }\end{array}$ & $\begin{array}{l}\text { Yes/No/Unclear } \\
\text { Yes/No/Unclear } \\
\text { Yes/No/Unclear } \\
\text { Yes/No/Unclear }\end{array}$ & & $\begin{array}{l}\text { Yes/No/Unclear } \\
\text { Yes/No/Unclear } \\
\text { Yes/No/Unclear } \\
\text { Yes/No/Unclear }\end{array}$ & & $\begin{array}{l}\text { Yes/No/Unclear } \\
\text { Yes/No/Unclear } \\
\text { Yes/No/Unclear } \\
\text { Yes/No/Unclear }\end{array}$ & \\
\hline $\begin{array}{l}\text { Attrition Bias } \\
\cdot \quad \text { Incomplete } \\
\text { outcome data } \\
\text { specified Reasons }\end{array}$ & $\begin{array}{l}\text { Yes/No/Unclear } \\
\text { Yes/No/Unclear }\end{array}$ & & $\begin{array}{l}\text { Yes/No/Unclear } \\
\text { Yes/No/Unclear }\end{array}$ & & $\begin{array}{l}\text { Yes/No/Unclear } \\
\text { Yes/No/Unclear }\end{array}$ & \\
\hline $\begin{array}{l}\text { Intention to } \\
\text { Treat }\end{array}$ & $\begin{array}{l}\text { All participants } \\
\text { entering trial }\end{array}$ & $\begin{array}{l}15 \% \text { or fewer ex- } \\
\text { cluded }\end{array}$ & $\begin{array}{l}\text { More than } 15 \% \\
\text { excluded }\end{array}$ & $\begin{array}{l}\text { Not analysed as } \\
\text { 'intention-to- } \\
\text { treat' }\end{array}$ & Unclear & $\begin{array}{l}\text { Were } \\
\text { withdrawals de- } \\
\text { scribed? Yes } \breve{S} \\
\text { No } \check{S} \quad \text { No } \breve{S} \\
\text { not clear } \breve{S}\end{array}$ \\
\hline
\end{tabular}

\section{Data extraction}




\section{Outcomes relevant to your review}

\begin{tabular}{|c|c|c|c|}
\hline & Treatment group & Comparison group 1 & Comparison group 2 (N/A) \\
\hline $\begin{array}{l}\text { Positive change to oral intake } \\
\text { status }\end{array}$ & Yes/No & Yes/No & Yes/No \\
\hline $\begin{array}{l}\text { Reduction or elimination of as- } \\
\text { piration or laryngeal penetra- } \\
\text { tion on food and/or fluids as } \\
\text { rated on objective assessment ( } \\
\text { videofluoroscopy, FEES) }\end{array}$ & Yes/No & Yes/No & Yes/No \\
\hline $\begin{array}{l}\text { Adverse events including in- } \\
\text { crease in swallowing problems, } \\
\text { compromised medical health, } \\
\text { negative psychological conse- } \\
\text { quences, negative social conse- } \\
\text { quences, hospitalisation, death }\end{array}$ & Yes/No & Yes/No & Yes/No \\
\hline $\begin{array}{l}\text { Client and/or carer satisfaction } \\
\text { with intervention }\end{array}$ & Yes / No & Yes / Nor & Yes / No \\
\hline $\begin{array}{l}\text { Reduction or elimination of } \\
\text { residue in the valleculae and/or } \\
\text { pyriform sinus/ post swallow }\end{array}$ & Yes/No & Yes/No & Yes/No \\
\hline Change in quality of life & Yes/No & Yes/No & Yes/No \\
\hline
\end{tabular}




\begin{tabular}{|c|c|c|c|c|c|c|c|}
\hline $\begin{array}{l}\text { Other infor- } \\
\text { mation which } \\
\text { you feel is rel- } \\
\text { evant to the } \\
\text { results } \\
\text { Indicate if: } \\
\text { any data were } \\
\text { obtained from } \\
\text { the primary } \\
\text { author; if re- } \\
\text { sults were es- } \\
\text { timated from } \\
\text { graphs etc; or } \\
\text { calculated by } \\
\text { you us- } \\
\text { ing a formula } \\
\text { (this should be } \\
\text { stated and the } \\
\text { formula } \\
\text { given). In gen- } \\
\text { eral if } \\
\text { results not re- } \\
\text { ported in pa- } \\
\text { per(s) are ob- } \\
\text { tained } \\
\text { this should be } \\
\text { made } \\
\text { clear here to be } \\
\text { cited in review }\end{array}$ & $\begin{array}{l}\text { Other infor- } \\
\text { mation which } \\
\text { you feel is rel- } \\
\text { evant to the } \\
\text { results } \\
\text { Indicate if: } \\
\text { any data were } \\
\text { obtained from } \\
\text { the primary } \\
\text { author; if re- } \\
\text { sults were es- } \\
\text { timated from } \\
\text { graphs etc; or } \\
\text { calculated by } \\
\text { you } \\
\text { ing a formula } \\
\text { (this should be } \\
\text { stated and the } \\
\text { formula } \\
\text { given). In gen- } \\
\text { eral if } \\
\text { results not re- } \\
\text { ported in pa- } \\
\text { per(s) are ob- } \\
\text { tained } \\
\text { this should be } \\
\text { made } \\
\text { clear here to be } \\
\text { cited in review }\end{array}$ & $\begin{array}{l}\text { Other infor- } \\
\text { mation which } \\
\text { you feel is rel- } \\
\text { evant to the } \\
\text { results } \\
\text { Indicate if: } \\
\text { any data were } \\
\text { obtained from } \\
\text { the primary } \\
\text { author; if re- } \\
\text { sults were es- } \\
\text { timated from } \\
\text { graphs etc; or } \\
\text { calculated by } \\
\text { you us- } \\
\text { ing a formula } \\
\text { (this should be } \\
\text { stated and the } \\
\text { formula } \\
\text { given). In gen- } \\
\text { eral if } \\
\text { results not re- } \\
\text { ported in pa- } \\
\text { per(s) are ob- } \\
\text { tained } \\
\text { this should be } \\
\text { made } \\
\text { clear here to be } \\
\text { cited in review }\end{array}$ & $\begin{array}{l}\text { Other infor- } \\
\text { mation which } \\
\text { you feel is rel- } \\
\text { evant to the } \\
\text { results } \\
\text { Indicate if: } \\
\text { any data were } \\
\text { obtained from } \\
\text { the primary } \\
\text { author; if re- } \\
\text { sults were es- } \\
\text { timated from } \\
\text { graphs etc; or } \\
\text { calculated by } \\
\text { you us- } \\
\text { ing a formula } \\
\text { (this should be } \\
\text { stated and the } \\
\text { formula } \\
\text { given). In gen- } \\
\text { eral if } \\
\text { results not re- } \\
\text { ported in pa- } \\
\text { per(s) are ob- } \\
\text { tained } \\
\text { this should be } \\
\text { made } \\
\text { clear here to be } \\
\text { cited in review }\end{array}$ & $\begin{array}{l}\text { Other infor- } \\
\text { mation which } \\
\text { you feel is rel- } \\
\text { evant to the } \\
\text { results } \\
\text { Indicate if: } \\
\text { any data were } \\
\text { obtained from } \\
\text { the primary } \\
\text { author; if re- } \\
\text { sults were es- } \\
\text { timated from } \\
\text { graphs etc; or } \\
\text { calculated by } \\
\text { you us- } \\
\text { ing a formula } \\
\text { (this should be } \\
\text { stated and the } \\
\text { formula } \\
\text { given). In gen- } \\
\text { eral } \\
\text { results not re- } \\
\text { ported in pa- } \\
\text { per(s) are ob- } \\
\text { tained } \\
\text { this should be } \\
\text { made } \\
\text { clear here to be } \\
\text { cited in review }\end{array}$ & $\begin{array}{l}\text { Other infor- } \\
\text { mation which } \\
\text { you feel is rel- } \\
\text { evant to the } \\
\text { results } \\
\text { Indicate if: } \\
\text { any data were } \\
\text { obtained from } \\
\text { the primary } \\
\text { author; if re- } \\
\text { sults were es- } \\
\text { timated from } \\
\text { graphs etc; or } \\
\text { calculated by } \\
\text { you us- } \\
\text { ing a formula } \\
\text { (this should be } \\
\text { stated and the } \\
\text { formula } \\
\text { given). In gen- } \\
\text { eral if } \\
\text { results not re- } \\
\text { ported in pa- } \\
\text { per(s) are ob- } \\
\text { tained } \\
\text { this should be } \\
\text { made } \\
\text { clear here to be } \\
\text { cited in review }\end{array}$ & $\begin{array}{l}\text { Other infor- } \\
\text { mation which } \\
\text { you feel is rel- } \\
\text { evant to the } \\
\text { results } \\
\text { Indicate if: } \\
\text { any data were } \\
\text { obtained from } \\
\text { the primary } \\
\text { author; if re- } \\
\text { sults were es- } \\
\text { timated from } \\
\text { graphs etc; or } \\
\text { calculated by } \\
\text { you us- } \\
\text { ing a formula } \\
\text { (this should be } \\
\text { stated and the } \\
\text { formula } \\
\text { given). In gen- } \\
\text { eral } \\
\text { results not re- } \\
\text { ported in pa- } \\
\text { per(s) are ob- } \\
\text { tained } \\
\text { this should be } \\
\text { made } \\
\text { clear here to be } \\
\text { cited in review }\end{array}$ & $\begin{array}{l}\text { Other infor- } \\
\text { mation which } \\
\text { you feel is rel- } \\
\text { evant to the } \\
\text { results } \\
\text { Indicate if: } \\
\text { any data were } \\
\text { obtained from } \\
\text { the primary } \\
\text { author; if re- } \\
\text { sults were es- } \\
\text { timated from } \\
\text { graphs etc; or } \\
\text { calculated by } \\
\text { you } \\
\text { ing a formula } \\
\text { (this should be } \\
\text { stated and the } \\
\text { formula } \\
\text { given). In gen- } \\
\text { eral } \\
\text { results not re- } \\
\text { ported in pa- } \\
\text { per(s) are ob- } \\
\text { tained } \\
\text { this should be } \\
\text { made } \\
\text { clear here to be } \\
\text { cited in review }\end{array}$ \\
\hline
\end{tabular}

\section{References to trial}

Check other references identified in searches. If there are further references to this trial link the papers now $\&$ list below. All references to a trial should be linked under one Study ID in RevMan.

\begin{tabular}{l|l|l|l}
\hline Code each paper & Author(s) & Journal/Conference Proceedings etc Year \\
\hline A & The paper listed above & \\
\hline B & Furtherpapers & \\
\hline
\end{tabular}

References to other trials 
Did this report include any references to published reports or unpublished data of potentially eligible trials not already identified for this review? If yes, give list contact name and details

\begin{tabular}{|c|c|c|}
\hline First author & Journal / Conference & Year of publication \\
\hline \multicolumn{3}{|c|}{ Overall Quality Score (GRADE rating) } \\
\hline \multirow{4}{*}{$\begin{array}{l}\text { High } \\
\text { Moderate } \\
\text { Low } \\
\text { Very low }\end{array}$} & & $\begin{array}{l}\text { High (Randomised trial /double upgraded Ix studies Further research } \\
\text { is very unlikely to change our confidence in the estimate of effect }\end{array}$ \\
\hline & & $\begin{array}{l}\text { Moderate: Downgraded randomised trials / Upgraded observational } \\
\text { studies Further research is likely to have an important impact on our } \\
\text { confidence in the estimate of effect and may change the estimate }\end{array}$ \\
\hline & & $\begin{array}{l}\text { Low: Double downgraded randomised trials/Observational studies } \\
\text { Low quality- Further research is very likely to have an important impact } \\
\text { on our confidence in the estimate of effect and is likely to change the } \\
\text { estimate }\end{array}$ \\
\hline & & $\begin{array}{l}\text { Very Low : Triple down graded randomised trials/downgraded obser- } \\
\text { vational studies/case series/case reports. Any estimate of effect is very } \\
\text { uncertain }\end{array}$ \\
\hline
\end{tabular}

\section{Review Author Comments:}

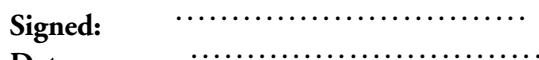

Date:

\section{CONTRIBUTIONSOFAUTHORS}

J Regan and M Walshe wrote the protocol. A Murphy developed the search strategy and performed the searches along with M Walshe, M Chiang and J Regan. B McMahon and T Coughlan reviewed the protocol.

\section{DECLARATIONS OF INTEREST}

The authors have no declaration of interest to report. 


\section{SOURCES OF SUPPORT}

\section{Internal sources}

- No sources of support supplied

\section{External sources}

- Health Research Board, Ireland.

Julie Regan is funded by the Health Research Board in Ireland under Grant No. HPF/2009/39. 